\title{
Small and minority farmers' knowledge and resource sharing networks, and farm sales: Findings from communities in Tennessee, Maryland, and Delaware
}

\author{
Aditya R. Khanal a* and Fisseha Tegegne a \\ Tennessee State University \\ Stephan J. Goetz b \\ Penn State University and Northeast Regional \\ Center for Rural Development \\ Lan $\mathrm{Li}^{\mathrm{c}}$ \\ Food and Agriculture Organization of the \\ United Nations
}

\author{
Yicheol Han d \\ Korea Rural Economic Institute
}

Stephan Tubene ${ }^{\mathrm{e}}$

University of Maryland-Eastern Shore

Andy Wetherill ${ }^{\mathrm{f}}$

Delaware State University

Submitted September 5, 2019 / Revised November 4 and December 5, 2019 / Accepted December 9, 2019 /

Published online April 17, 2020 / Updated April 18, 2020, with author affiliations

Citation: Khanal, A. R., Tegegne, F., Goetz, S J., Li, L., Han, Y., Tubene, S., \& Wetherill, A. (2020). Small and

minority farmers' knowledge and resource sharing networks, and farm sales: Findings from communities in

Tennessee, Maryland, and Delaware. Journal of Agriculture, Food Systems, and Community Development, 9(3), 149-162.

https://doi.org/10.5304/jafscd.2020.093.012

Copyright (C) 2020 by the Authors. Published by the Lyson Center for Civic Agriculture and Food Systems. Open access under CC-BY license.

\begin{abstract}
A network analysis can quantify the depth and breadth of a farmer's relationships with other local farmers, buyers and sellers, or other groups and

${ }^{a}$ Department of Agricultural and Environmental Sciences, College of Agriculture, Tennessee State University, Nashville, Tennessee, USA.

b Penn State University and Northeast Regional Center for Rural Development (NERCRD), Pennsylvania, USA.

c Agricultural Development Economics Division, Food and Agriculture Organization of the United Nations (FAO). At the time of part of this research, Li was at the College of Agriculture of Tennessee State University, Tennessee, USA.

${ }^{\mathrm{d}}$ Korea Rural Economic Institute, Republic of Korea. Han was formerly at Penn State University and the Northeast Regional Center for Rural Development, Pennsylvania, USA.

e Department of Agriculture, Food and Resource Sciences, University of Maryland-Eastern Shore, Maryland, USA.
\end{abstract}

organizations. Such an analysis can potentially also reveal farmers' incentives, situations, and behaviors, and it may explain their economic success more generally. This study examines small and minority farmers' networks using a primary survey

${ }^{\mathrm{f}}$ College of Agriculture-Cooperative Extension Program, Delaware State University, Delaware, USA.

* Corresponding author: Aditya R. Khanal, akhanal1@,Tnstate.edu

\section{Funding Disclosure}

This paper is based on data generated under the objectives of the project "Enhancing the Viability of Underserved Small Farms and Rural Communities using Insights from Emerging Network Science" (Grant \#2011-38821-30966). We gratefully acknowledge U.S. Department of Agriculture (USDA) National Institute of Food and Agriculture (NIFA) funding, as well as the support of the Northeast Research Association, Penn State's College of Agricultural Sciences, and the College of Agriculture at Tennessee State University. 
in three farming communities. We emphasize networks related to production, marketing, and resource-sharing activities of 127 farmers (nodes) in Tennessee, 46 in Maryland, and 23 in Delaware, and compute three different measures of network importance or "centrality" for each farmer. We then use generalized least squares analysis relating farmer's age, gender, race, educational attainment, labor use on the farm, and farm location to the farmer's centrality position or importance in the network, defined by number and strength of links or connections. In additional regression analyses, we find significantly positive effects of the centrality position on farm sales of specialty crops: our model predicts that a farmer who adds one additional link or connection can expect a 19\% to $25 \%$ increase in sales, all else equal. Our results can potentially be used not only to disseminate information more efficiently, but also to identify farmers who would benefit the most from more targeted extension services.

\section{Keywords}

Farmer Networks, Minority Farmers, Centrality, Small Farmers, Network Analysis, Farm Financial Performance, Specialty Crops, Knowledge Sharing

\section{Introduction}

Knowledge about new agricultural practices and technology is often diffused through human interactions, whereby network structures as well as informant characteristics are critical. This is especially important for small and minority-owned rural farms: to compete with larger farms, such operations require access not only to new production and technology resources on the input side, but also to market outlets, including niche opportunities (Khanal \& Mishra, 2014; Pratiwi \& Suzuki, 2017). Information sources available to farmers include formal (e.g., university- or government-based Cooperative Extension) and informal social networks (Boahene, Snijders, \& Folmer, 1999; Conley \& Udry 2010; Lyon, 2000), as well as interpersonal relationships with peers, among others (Pratiwi \& Suzuki, 2017).

The theory of social networks examines how nodes - consisting of individuals, firms, and organizations - interact with one another, where interac- tions are represented as links (McClure, Frierson, Hall, \& Ostlund, 2017). The literature on innovation and information diffusion is based on "social learning," and includes studies of cultural evolution and social capital development (e.g., Hoffman, Lubell, \& Hillis, 2015; Shaw, Lubell, \& Ohmart, 2011). Innovation diffusion is often a byproduct of the actual adoption of technology, which can be enhanced if it occurs in an environment with strong social networks. In addition, culture evolves through social network-based exchanges as individuals copy and adopt ideas or suggestions made by individuals who are perceived as leaders (Richerson \& Boyd, 2005). The trust that is represented by social capital may be most valuable when it is used to address local problems involving the provision of public goods (Coleman, 1990; Flora \& Flora, 2008; Rupasingha \& Goetz, 2007). The strength of trustbased relationships is immensely important for cooperation among specific groups, such as disadvantaged and minority farmer groups (Beratan, Jackson, \& Godette, 2014). Individual and community cooperation and interactions among farmers and between groups can help build their capacity in new entrepreneurial opportunities (Beratan et al., 2014) and local agri-food systems (Dunning et al., 2012). It can also mitigate problems such as food insecurity in urban agriculture settings (Meenar \& Hoover, 2012).

Social network analysis (SNA) is now widely used in diverse contexts to understand relationships among individuals and groups, including farmers embedded within supply chains. The latter are known as nodes, or hubs, and their connections are defined as edges, or links. Many different network measures can be calculated, but density and inter-node or intra-network distance are among the most common, allowing comparisons of networks with others as well as over time (Han \& Goetz, 2019). Applications of SNA range from trade and agriculture (Kim \& Shin, 2002) to biodiversity (Hauck, Schmidt, \& Werner, 2016), forestry (Keskitalo, Baird, Laszlo Ambjörnsson, \& Plummer, 2014), and regional food system analysis (Christensen \& O’Sullivan, 2015).

At the same time, SNA has not been used widely to assess the performance of individual farms, especially in the context of small, minority- 
operated farms in the US. Our study addresses this limitation by examining how small and minority farmers' participation and position within social networks affects farm performance. First, using primary data, we assess small farmers' production-, marketing-, and information-sharing networks and each farmer's network position and centrality. Second, we analyze the roles that network position plays in farm performance in terms of specialty crop sales. We use primary survey data of small (-scale) farmers in Tennessee, Maryland, and Delaware to empirically address these questions.

\section{Method}

\section{Network Concepts}

Social networks and relations are commonly represented as graphs showing nodes and links, which are referred to as social network analysis (SNA) maps. In directed networks, each link has an origin and a destination. Node centrality is an important concept in network studies and can be measured in terms of the degree, closeness, or betweenness score of the node, which in our case is a farmer (Freeman, 1978; Opsahl, Agneessens, \& Skyoretz, 2010; Prell, Hubacek, \& Reed, 2009). Another feature is that of symmetry: if A knows B, B should also know $A$. However, if A seeks information from B but not vice versa, then the resulting link is not symmetric.

The number of ties a node has with other nodes is known as degree centrality. For directed links, two types are calculated: (a) degrees-in centrality: the number of incoming connections or links to the node, and (b) degree-out centrality: the number of connections a node has to others, or the count of out-going links. A higher in-degree centrality suggests greater popularity or "prestige" of the node, which may be helpful for rapidly spreading new information to others (Prell et al., 2009). A higher out-degree is usually associated with greater sociability or "gregariousness."

Closeness centrality measures the extent to which an individual is "near" all other individuals in the network (Opsahl et al., 2010). In the case of a directed link, closeness centrality again includes a) closeness-in: which is based on the average length of the path to the node, which affects how quickly information or goods can be received from other from nodes, and b) closeness-out: which is analogous, but on the outflow side. A node with a high out-closeness value can diffuse new information without needing many other nodes or intermediaries in the transmission (Opsahl et al., 2010).

Betweenness centrality measures the frequency with which a node lies on the immediate path between other nodes (Opsahl et al., 2010; Prell et al., 2009). It reflects the relative importance of a node in serving as an "intermediary" (or bridge) between other nodes. This measure is important and distinctive in that it also reflects the ability of a node to control information diffusion or flow within the network. Individuals with high betweenness scores tend to have a high degree of control; they can enhance or restrict information flows and also control who sees or is informed of a particular item. In this paper, we assess small farmers' networks by computing degree-, closeness-, and betweennesscentralities of each farmer, because each measure subtly captures a different quality of importance within the network.

\section{Modeling the Factors Influencing Network Positions} Consider farmer $\mathrm{i}$ who has centrality position $\mathrm{k}$, defined as $P_{i}^{k}$ in network $\mathrm{Z}$ where $k=\{$ degree in, degree out, closeness in, closeness out, betweenness $\}$. We are interested in how vector $X_{i}$ of demographic and socioeconomic exogenous factors influence the centrality position of farmer i:

$$
P_{i}^{k}=f\left(X_{i}\right)
$$

We include respondent (farmer) age, education, ethnicity, and internet access as possible determinants of network centrality position.

\section{Modeling Network Influence on Farm Performance}

This section discusses the empirical method used to analyze and test hypotheses on the relationship between centrality positions and farm performance. An individual farmer $i$ s farm performance (e.g., farm sales) can be represented as a function of several demographic, socio-economic, and managerial characteristics, including the network ability: 
Figure 1. Conceptual Framework Showing Relationship of Small and Minority Farmers' Social Networks and Farm Performance

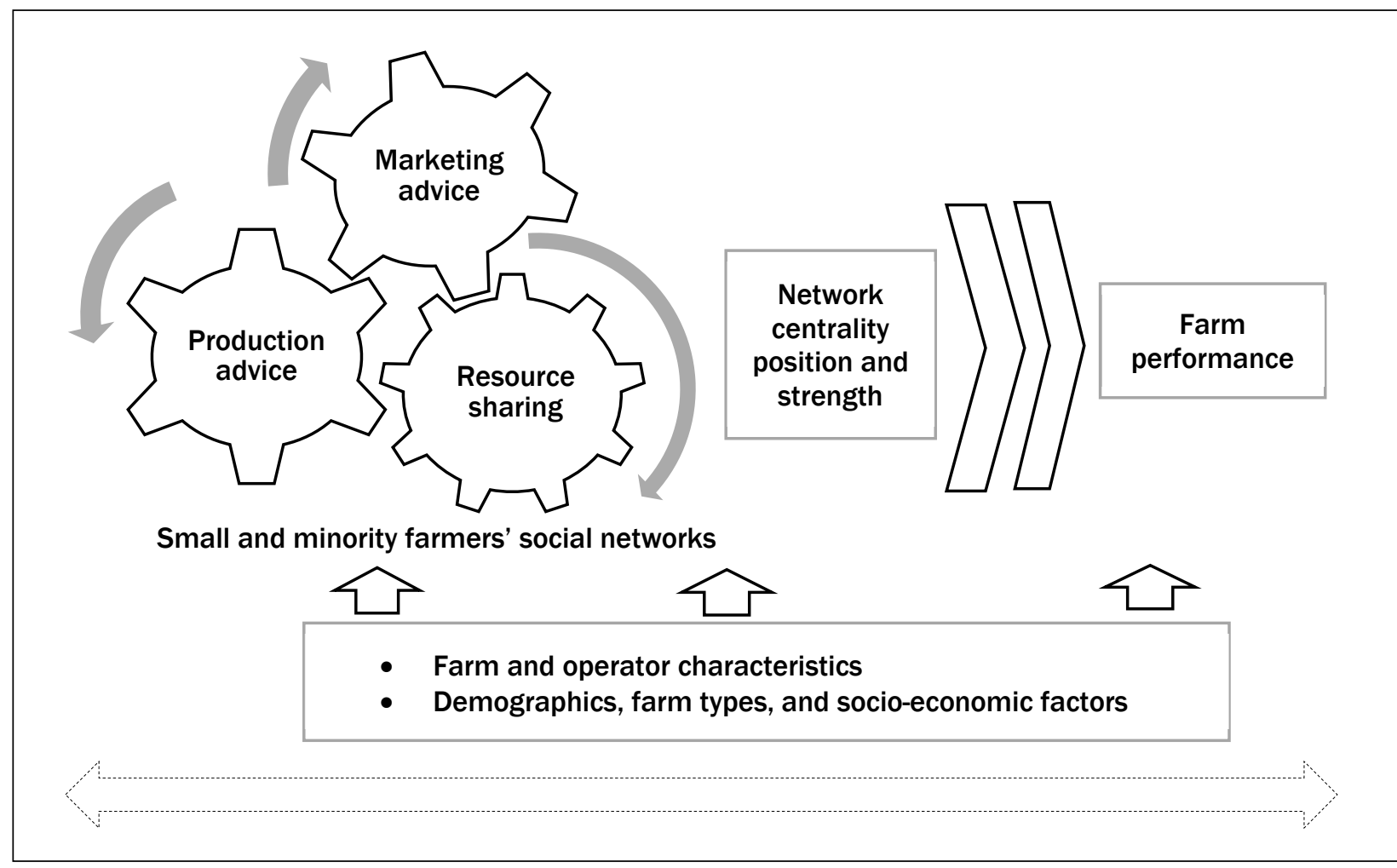

$$
S_{i}=f\left(X_{i}, P_{i}^{k}\right)
$$

Here $S_{i}$ represents farm performance of farmer $i$ and $X_{i}$ and $P_{i}^{k}$ are as defined previously. We use OLS to examine this relationship statistically.

Figure 1 shows the overall conceptual theme of the paper. Small and minority farmers potentially utilize networks in production, marketing, and resource sharing where within- and between-network interactions and associated network strength and centrality position, along with demographics, farm, and farmer characteristics, significantly influence the farm performance (Figure 1).

\section{Data}

In this study, information was collected from small and minority farmers in three states: Tennessee, Delaware, and Maryland, as per the objectives of the project funded by the U.S. Department of Ag- riculture, National Institute of Food and Agriculture (USDA NIFA). Surveys of farmers were conducted in 2012-2013 through Tennessee State University, University of Maryland-Eastern Shore, and Delaware State University. The study focused on small farms and producers growing and selling specialty crops. Employing different means of survey administration, follow-up, and reminders among small farmers, we identified 127 total nodes in Tennessee, 46 in Maryland, and 23 in Delaware networked for production advice, marketing advice, and resource sharing. These nodes were used for network graphing and calculating centrality scores. For the econometric analysis and model estimation requiring demographic and socio-economic information of each farmer, 117 observations with complete information were used. The steps in data collection are described in the following subsections. These steps are also described in the training manual published as a project output. ${ }^{1}$

${ }^{1}$ https://aese.psu.edu/nercrd/publications/rdp/network-analysis-of-farmer-groups 


\section{Identifying Network and Sample Design}

A first step in carrying out a network analysis is identifying the group of farmers and others who should be included. We sought help from established Cooperative Extension program representatives in each state who have direct, day-to-day connections with farmers during various activities of land-grant universities.

In Tennessee, the network covered six counties (Davidson, Montgomery, Rutherford, Shelby, Hardeman, and Franklin), three of which are adjacent to metro areas. Each county provided a list of pre-identified producers. These farmers were identified from lists maintained by county Extension offices. The pre-identified list included small vegetable farmers (we excluded large commodity producers from the study). We also excluded those potential respondents who reside in the same household and work on the same farm. The farmers were given space on the survey instrument to add other farmers not in the list; duplicated names were dropped. This survey of producers generated demographic and economic information of the operators such as age, experience, education, gender, ethnicity, and farming plans, as well as information on their farm production and sales. All counties had adequate numbers of farmers who provided useful network information.

In Delaware and Maryland, we used a number of criteria to identify and select samples for the network identification and analysis. In Delaware, we used the master list of producers maintained in the University's Cooperative Extension program. Large-scale producers were again excluded from the survey, for the most part. Even though the state university is open to providing technical assistance to large producers, considerable time was spent expanding opportunities for limited, small, and minority producers in the state and ensuring that producers from all counties in the state were represented. One additional selection criterion was to identify producers with specialty crops and the potential to market fresh agricultural produce and value-added products in neighboring metropolitan areas. In Maryland, we also examined the agroecological zone of the state and chose areas known for growing high-value crops. Farmers were reached by phone using a database of commercial small farmers and ranchers maintained by the university. Some farmers were contacted at the small farm conferences and meetings organized by the university. Farmers selected were a mix of landowners and leaseholders growing a variety of products ranging from high-value vegetables (e.g., hot peppers, eggplants, okra, amaranth) to cut flowers and mushrooms, and garden-raised eggs. We used a list of small-scale farmers, which included socially disadvantaged farmers and detected two subnetworks within the overall network in Maryland.

\section{Survey Questionnaire Design and Administration}

Once the list of farmers was compiled, we developed and administered a survey for the network analysis. The survey questionnaire consisted of different components. If the population to be surveyed (the list identified) was not too large, survey respondents were asked to fill out the table or matrix that listed farmers across the top as well as down the rows. If the list was very long, farmers were asked to write down (across columns, with one per farmer) with whom they have a network relationship. Farmers were also asked about the nature of their network relationships, such as advice and resource exchange, if any, with the other farmers in the network. They were also provided space allowing them to add other individuals who were not listed. A second component of the questionnaire asked about network relationships. From the list of farmers (or the completed list after the respondent added names), each respondent was asked to enter the number corresponding to the other farmer with whom a relationship exists. To find the nature of the relationship, the following questions were asked: Among these farmers, which one would you go to, to get information about a production problem? Who do you go to for a marketing problem? Who do you ask for advice on how to apply for credit or file taxes? Who do you ask for advice on agriculturally related information? The third component of the questionnaire asked about production and sales, incomes, and demographic characteristics of farm operators.

Different strategies were used to obtain a high response rate from farmers. In Delaware and Maryland, strategies included mailing surveys and repeatedly following up; administering surveys at the farmer meetings, field days, and extension events; 
and direct visits to farmers for one-on-one meetings after events. In Tennessee, the survey was conducted face-to-face among identified small fruit and vegetable growers in five counties. The venue for the survey in all cases was the county Extension office; county Extension educator assistance was instrumental in conducting the survey.

\section{Results and Discussion}

We present summary statistics of the variables in Table 1. As noted, our network analysis results are based on the responses of 117 individual smallscale, minority farmers - 56\% from Tennessee, 26\% from Maryland, and 19\% from Delaware (Table 1). Table 1 also shows degree-in, degree-out,

Table 1. Summary Statistics of the Variables Used in this Study

\begin{tabular}{|c|c|c|c|}
\hline Variable & Definition & Mean & Stand. Dev. \\
\hline \multicolumn{4}{|c|}{ Network centrality measures } \\
\hline Degree-in & The number of connections directed to the node (number) & 1.094 & 1.687 \\
\hline Degree-out & The number of connections the node directs to other (number) & 1.846 & 2.176 \\
\hline Closeness-in & Inverse of total shortest path length directed to the node & 0.010 & 0.015 \\
\hline Closeness-out & Inverse of total shortest path length the node directs to others & 0.018 & 0.020 \\
\hline Betweenness & $\begin{array}{l}\text { The number of times the node lies between the shortest path of two other } \\
\text { nodes (controllability of information flow) }\end{array}$ & 5.012 & 14.304 \\
\hline \multicolumn{4}{|c|}{ Farm performance measures } \\
\hline Farm Sales & Total annual specialty crop sales from farm (in US dollars) & $\$ 15,508$ & $\$ 22,973$ \\
\hline \multicolumn{4}{|c|}{ Characteristics of farmer/ farm operator } \\
\hline Agebelow35 & $=1$ if farmer/operator is equal or below to 35 years old & $10.26 \%$ & \\
\hline Age36to54 & $=1$ if farmer/operator is between to 35 to 34 years old & $31.62 \%$ & \\
\hline Age55to64 & $=1$ if farmer/operator is between to 35 to 64 years old & $25.64 \%$ & \\
\hline Ageabove65 & $=1$ if farmer/operator is equal to above 65 years old & $32.48 \%$ & \\
\hline Gender: Female & $=1$ if farmer/operator is female & $28.21 \%$ & \\
\hline Race: White & $=1$ if farmer/operator considers his(her) race as White & $39.32 \%$ & \\
\hline $\begin{array}{l}\text { African American/ } \\
\text { rican }\end{array}$ & $=1$ if farmer/operator considers his(her) race as African American or African & $44.44 \%$ & \\
\hline Hispanic/Latino & $=1$ if farmer/operator considers his(her) race as Hispanic/Latino & $2.56 \%$ & \\
\hline Asian & $=1$ if farmer/operator considers his(her) race as Asian & $11.11 \%$ & \\
\hline Multiracial & $=1$ if farmer/operator considers his(her) race as multiracial & $2.56 \%$ & \\
\hline$<$ High School & $=1$ if education level of farmer/operator is below high school & $8.55 \%$ & \\
\hline High School & $=1$ if education level of farmer/operator is high school & $25.64 \%$ & \\
\hline Some College & $=1$ if farmer/operator has some college level education & $23.08 \%$ & \\
\hline 4-yr Undergrad & $=1$ if farmer/operator has 4-year undergraduate level education & $28.21 \%$ & \\
\hline Grad and above & $=1$ if farmer/operator has graduate or higher level education & $14.53 \%$ & \\
\hline Married & $=1$ if farmer/operator is married & $71.05 \%$ & \\
\hline Fulltime farming & $=1$ if farmer/operator considers him (her) as full-time farmer & $56.41 \%$ & \\
\hline Family labor use & $=1$ if farm operation uses family labor for farm activities & $82.05 \%$ & \\
\hline Hired labor use & $=1$ if farm operation uses hired labor & $37.61 \%$ & \\
\hline Internet access & $=1$ if farmer has Internet access & $76.92 \%$ & \\
\hline Years farming & Number of years the farmer/operator is in farming & 27.05 & 20.79 \\
\hline Delaware State & $=1$ if farm is located in Delaware state & $18.80 \%$ & \\
\hline Maryland State & $=1$ if farm is located in Maryland state & $25.64 \%$ & \\
\hline Tennessee State & $=1$ if farm is located in Tennessee state & $55.56 \%$ & \\
\hline \multicolumn{2}{|c|}{ Number of observations } & 117 & \\
\hline
\end{tabular}

Source: Primary survey of small farmers, by authors, 2012-2013. 
closeness-in, closeness-out, and betweenness centrality as network measures. The average farmer has one incoming link (1.09 degree-in) and two outgoing links (1.85 degree-out). This indicates that at least one other farmer is connected to each farmer who, on average, connects to two other farmers in this nonsymmetrical network. Also, a relatively higher betweenness centrality (average score of 5.01 in our sample) reveals that each farmer lies between the network (or information) flow paths of 5 other farmers-which indicates that each small farmer can control information flow among the other farmers in the network; this score also has a relatively high standard deviation (14.3).

Other descriptive sample statistics show characteristics of the farmers in our sample and of their farms. On average, farms generated around US $\$ 15,500$ in annual sales from specialty crops, confirming that the sample includes a high percentage of very small farmers. Around $32 \%$ of sampled farmers were above 65 years of age, $32 \%$ were between 36 to 54 years; in terms of race/ethnicity, $44 \%$ were African American, followed by 39\% White and 11\% Asian. Regarding education level, $28 \%$ of sampled farmers had a 4-year undergraduate degree, and $26 \%, 23 \%$, and $15 \%$ had a high school degree, some college, and graduate-level de- grees, respectively. Around $56 \%$ of the sampled farmers were farming full time, $82 \%$ involved family members as labor, while $37 \%$ also hired labor onto the farm; most (71\%) were married and had internet access $(77 \%)$ for use in different farm-related activities (Table 1).

Table 2 shows descriptive information specific to the network by state. In the entire network, 86 out of 127 (around 68\%) of the farmers in Tennessee, 19 of the 23 nodes (82.6\%) in Delaware and 29 of 46 nodes (63\%) in Maryland had at least one connection whether it was in terms of production, marketing advice, or sharing resources. Sharing of resources was more common in Delaware $(82.6 \%$, 19 out of 23 total possible connections) than in the other two states, with $43.5 \%$ and $44.9 \%$ respectively in Maryland and Tennessee. Using a network for marketing advice was more or less similar in all three states $(56.5 \%, 52.2 \%$, and $48.8 \%$ in Delaware, Maryland, and Tennessee, respectively). As shown by the degree centrality networks, farmers in Delaware were most densely connected, followed by those in Tennessee, and Maryland. This may reflect the result that there are fewer farmers in the Delaware farming community and, therefore, they may live relatively close to one another and, as a result, know each other better than is the case in the other two states.

Table 2. Summary of Network Connection Types and Network Centrality Among Small Farmers

\begin{tabular}{|c|c|c|c|c|c|c|c|}
\hline State & connection type & $\begin{array}{c}\text { total } \\
\text { nodes }\end{array}$ & $\begin{array}{c}\text { connected } \\
\text { nodes }\end{array}$ & degree & closeness-in & closeness-out & betweenness \\
\hline \multirow{4}{*}{ Delaware } & entire & \multirow{4}{*}{23} & 19 & 2.65 & 0.1999 & 0.2014 & 5.83 \\
\hline & production advice & & 18 & 1.57 & 0.1307 & 0.1319 & 5.57 \\
\hline & marketing advice & & 13 & 1.13 & 0.0647 & 0.0640 & 2.52 \\
\hline & sharing resources & & 19 & 2.52 & 0.1880 & 0.1868 & 5.39 \\
\hline \multirow{4}{*}{ Maryland } & entire & \multirow{4}{*}{46} & 29 & 0.76 & 0.0238 & 0.0242 & 1.02 \\
\hline & production advice & & 24 & 0.67 & 0.0211 & 0.0211 & 0.93 \\
\hline & marketing advice & & 24 & 0.67 & 0.0211 & 0.0211 & 0.93 \\
\hline & sharing resources & & 20 & 0.30 & 0.0076 & 0.0079 & 0.09 \\
\hline \multirow{4}{*}{ Tennessee } & entire & \multirow{4}{*}{127} & 86 & 1.02 & 0.0128 & 0.0130 & 4.02 \\
\hline & production advice & & 72 & 0.70 & 0.0074 & 0.0076 & 1.35 \\
\hline & marketing advice & & 62 & 0.53 & 0.0049 & 0.0049 & 0.42 \\
\hline & sharing resources & & 57 & 0.59 & 0.0069 & 0.0070 & 1.80 \\
\hline
\end{tabular}

Source: Computation based on primary survey of small farmers, 2012-2013. 
Networking for resource sharing is most dense in Delaware (possibly because of smaller individual farm size and the reason mentioned previously), while networking for production and marketing advice is densest in Maryland, and networking for production advice is more densely connected in Tennessee networks. In Maryland, the Extension educator may be helping farmers to access ethnic communities along the densely settled eastern seaboard (e.g., Washington, D.C.), which may account for this result. Sharing of resources had the lowest density in Maryland, perhaps because farmers there are better off and can afford to purchase their own resources.

Closeness and betweenness measures further explain patterns in the degrees, and these measures are related to some extent. In and out closeness for the 'entire' measure is larger in Maryland than in Tennessee, though the degree is higher in Tennessee. Therefore, the average density of connections indicated by degrees is higher in Tennessee than Maryland, but closeness is lower. It is interesting to look at the betweenness measure for 'entire': Tennessee has a higher value than Maryland, which indicates that farmers in Tennessee are more likely to be positioned between the connections of other nodes, which reduces the closeness measure. Moreover, the betweenness score is highest in Delaware, followed by Tennessee and Maryland. In Delaware, the betweenness score for production advice (5.57) is higher than that for sharing resources (5.39), even though the opposite is true for the average degrees (1.57 vs. 2.52). This indicates that individuals more often lie between the connections of other nodes in terms of production advice than sharing of resources. This also explains the lower closeness score in production advice than in sharing resources.

\section{Factors Influencing Network Centrality Positions}

Table 3 shows our regression estimation results for the factors influencing a farmer's network centrality position. We used a negative binomial regression fitted using a maximum likelihood estimator. This is appropriate for the count nature of the dependent variable given that our degree measures are non-negative counts. The bottom rows of the table show overall model statistics. A significant dispersion parameter (alpha) suggests a higher suitability and fit of the negative binomial compared to other count data models (specifically, the Poisson model) in our case. Additionally, a pseudo- $\mathrm{R}^{2}$ of 0.14 and 0.13 suggests a reasonably good fit of our non-linear models (considering the small sample size).

Our estimated coefficients suggest that factors such as farmer's age, gender, race, educational attainment, labor use on the farm, and farm location significantly affect the farmer's centrality position (measured by degree-in and degree-out) in the networks. Results in Table 3 suggest that the farmer's age is positively associated with centrality position; specifically, farmers 65 years and older are more likely to have higher degree-in centrality, while those 55 to 65 years are more likely to have higher degree-out centrality as compared to relatively younger farmers (base: less than 35 years). This suggests that other farmers connect to relatively older and experienced farmers to seek their advice, perhaps valuing their experience. A gender effect is shown in degree-out equations suggesting that female-owned or -operated farms have lower degreeout centrality - indicating that these farms are likely to connect to fewer other farmers compared to male-owned or -operated farms. This result is somewhat unexpected. However, this may reflect the characteristics of this particular population, where female farmers are less outgoing. The data collected on race suggests that African American farmers are likely to be connected to a larger number of other farmers (in terms of both seeking advice and providing advice) as compared to White farmers, while Asian farmers are contacted by more other farmers, but do not necessarily reach out to others in the network for advice. Multiracial operators, on the other hand, are likely to be connected by fewer other farmers in the network, as compared to White farmers.

Table 3 also shows that educational attainment has a positive impact on degree-in centrality and a negative impact on degree-out centrality. Specifically, farmers with graduate-level education or above are likely to have higher degree-in (more people connect to them) as compared to those with less than a high school education. Negative coefficients on the higher education variables of 
Table 3. Factors Influencing Network Centrality Position

\begin{tabular}{|c|c|c|c|c|}
\hline \multirow[b]{2}{*}{ Variable } & \multicolumn{2}{|c|}{ Degree-in } & \multicolumn{2}{|c|}{ Degree-out } \\
\hline & Coefficient & Standard Error & Coefficient & Standard Error \\
\hline Constant & -1.931 & 1.143 & 0.914 & 0.777 \\
\hline \multicolumn{5}{|c|}{ Age (Base: less than or equal to 35 years) } \\
\hline Age36to54 & 0.089 & 0.567 & 0.059 & 0.252 \\
\hline Age55to64 & 0.964 & 0.748 & $1.028 * * *$ & 0.399 \\
\hline Age65\&above & $0.615 * * *$ & 0.280 & 0.531 & 0.565 \\
\hline Married & $0.342 * * *$ & 0.137 & -0.147 & 0.186 \\
\hline Female & -0.124 & 0.216 & $-0.313^{*}$ & 0.173 \\
\hline \multicolumn{5}{|l|}{ Race (base: White) } \\
\hline African American & $1.357 * * *$ & 0.435 & $0.978 * * *$ & 0.217 \\
\hline Hispanic & 0.0836 & 0.837 & 0.214 & 0.582 \\
\hline Asian & $1.244 * * *$ & 0.631 & 0.144 & 0.402 \\
\hline Multiracial & $-17.867 * * *$ & 0.911 & 0.685 & 0.858 \\
\hline \multicolumn{5}{|l|}{ Education level (base: < high school) } \\
\hline High school & $0.879 *$ & 0.504 & -0.440 & 0.319 \\
\hline Some college & 0.472 & 0.534 & $-0.692 * * *$ & 0.261 \\
\hline 4-year undergrad degree & 0.770 & 0.508 & $-1.062 * * *$ & 0.395 \\
\hline Graduate education and above & $1.205 * * *$ & 0.621 & $-0.925 * * *$ & 0.416 \\
\hline Full time farmer & -0.025 & 0.392 & -0.294 & 0.301 \\
\hline Family labor use & 0.100 & 0.337 & -0.065 & 0.161 \\
\hline Hired labor use & $0.473 * * *$ & 0.170 & 0.257 & 0.218 \\
\hline Internet access & -0.509 & 0.444 & 0.109 & 0.183 \\
\hline \multicolumn{5}{|l|}{ Location (Base: Delaware state) } \\
\hline Maryland & $-1.151 * * *$ & 0.544 & $-0.516 * * *$ & 0.229 \\
\hline Tennessee & -0.336 & 0.394 & -0.139 & 0.283 \\
\hline Dispersion parameter $(\propto)$ & $0.560 *$ & 0.301 & $0.300 *$ & 0.159 \\
\hline Pseudo R2 & & 0.144 & & 0.131 \\
\hline Number of observations & & 117 & & 117 \\
\hline
\end{tabular}

Parameters are estimated using negative binomial regressions appropriate for count data with dispersion; *, **, *** indicate $10 \%, 5 \%$, and $1 \%$ level of significance, respectively.

some college, undergraduate, and graduate-level \& above in the degree-out equation suggest that farmers with relatively higher education levels connect to fewer other farmers, as compared to those with less than high school education. Overall, this education effect is consistent with expectations: compared to the less than high school educated, farmers with a higher level of education are expected to be contacted by more other individuals for advice, but are less likely to seek advice from their peers in the network. Our results also suggest that compared to Delaware farmers, Maryland farmers were significantly more likely to have lower degree-in and degree-out numbers.

\section{The Impact of Network Centrality on Farm Sales}

Table 4 presents our estimation results for the impact of network centralities on farm sales. Recall that farm sales are the annual total farm sales from specialty crops (in US dollars). We used a generalized linear poisson model suitable for our sales variable reported as non-negative integers. 
Table 4. Equations Estimating the Effect of Network Centrality on Farm Sales

\begin{tabular}{|c|c|c|c|}
\hline & Model 1 & Model 2 & Model 3 \\
\hline Variable & Parameter Estimate & Parameter Estimate & Parameter Estimate \\
\hline Constant & $\begin{array}{l}10.676 * * * \\
(0.421)\end{array}$ & $\begin{array}{l}10.085 * * * \\
(0.507)\end{array}$ & $\begin{array}{l}10.736 * * * \\
(0.408)\end{array}$ \\
\hline Degree-in centrality & $\begin{array}{l}0.189 * * * \\
(0.063)\end{array}$ & & \\
\hline Degree-out centrality & & $\begin{array}{l}0.246 * * * \\
(0.054)\end{array}$ & \\
\hline Betweenness centrality & & & $\begin{array}{l}0.034 * \\
(0.020)\end{array}$ \\
\hline \multicolumn{4}{|c|}{ Age (Base: less than or equal to 35 years) } \\
\hline Age36to54 & $\begin{array}{l}0.687 * * \\
(0.303)\end{array}$ & $\begin{array}{l}0.744 * * \\
(0.318)\end{array}$ & $\begin{array}{l}0.664 * * \\
(0.298)\end{array}$ \\
\hline Age55to64 & $\begin{array}{c}0.149 \\
(0.199)\end{array}$ & $\begin{array}{c}0.135 \\
(0.283)\end{array}$ & $\begin{array}{c}0.176 \\
(0.227)\end{array}$ \\
\hline Age65\&above & $\begin{array}{c}0.038 \\
(0.187)\end{array}$ & $\begin{array}{c}0.049 \\
(0.223)\end{array}$ & $\begin{array}{c}-0.083 \\
(0.196)\end{array}$ \\
\hline Married & $\begin{array}{l}-0.724 * * * \\
(0.168)\end{array}$ & $\begin{array}{l}-0.742 * * * \\
(0.175)\end{array}$ & $\begin{array}{l}-0.593 * * * \\
(0.142)\end{array}$ \\
\hline Female & $\begin{array}{l}-0.629 * * * \\
(0.193)\end{array}$ & $\begin{array}{l}-0.571 * * * \\
(0.147)\end{array}$ & $\begin{array}{l}-0.643 * * * \\
(0.188)\end{array}$ \\
\hline \multicolumn{4}{|l|}{ Race (base: White) } \\
\hline African American & $\begin{array}{l}-2.259 * * * \\
(0.409)\end{array}$ & $\begin{array}{l}-2.557 * * * \\
(0.448)\end{array}$ & $\begin{array}{l}-2.165 * * * \\
(0.403)\end{array}$ \\
\hline Hispanic & $\begin{array}{l}-2.936 * * * \\
(0.272)\end{array}$ & $\begin{array}{c}-3.278 \\
(0.271)\end{array}$ & $\begin{array}{l}-3.125 * * * \\
(0.285)\end{array}$ \\
\hline Asian & $\begin{array}{l}-0.818 * * * \\
(0.286)\end{array}$ & $\begin{array}{l}-0.573 * * \\
(0.267)\end{array}$ & $\begin{array}{l}-0.691 * * * \\
(0.280)\end{array}$ \\
\hline Multiracial & $\begin{array}{l}-1.841 * * * \\
(0.476)\end{array}$ & $\begin{array}{l}-1.298 * * * \\
(0.300)\end{array}$ & $\begin{array}{l}-1.877 * * * \\
(0.401)\end{array}$ \\
\hline \multicolumn{4}{|c|}{ Education level (base: less than high school) } \\
\hline High school & $\begin{array}{l}0.561 * * \\
(0.252)\end{array}$ & $\begin{array}{l}1.018 * * * \\
(0.242)\end{array}$ & $\begin{array}{l}0.654 * * * \\
(0.226)\end{array}$ \\
\hline Some college & $\begin{array}{l}0.760 * * * \\
(0.319)\end{array}$ & $\begin{array}{l}1.063 * * * \\
(0.214)\end{array}$ & $\begin{array}{l}0.743 * * * \\
(0.291)\end{array}$ \\
\hline 4-year undergrad degree & $\begin{array}{c}0.339 \\
(0.473)\end{array}$ & $\begin{array}{c}0.676 \\
(0.430)\end{array}$ & $\begin{array}{c}0.236 \\
(0.473)\end{array}$ \\
\hline Graduate educ. and above & $\begin{array}{l}0.719 * * \\
(0.364)\end{array}$ & $\begin{array}{l}0.911 * * * \\
(0.343)\end{array}$ & $\begin{array}{l}0.719 * \\
(0.404)\end{array}$ \\
\hline Full time farmer & $\begin{array}{l}-0.987 * * * \\
(0.293)\end{array}$ & $\begin{array}{l}-0.834 * * * \\
(0.233)\end{array}$ & $\begin{array}{l}0.970 * * * \\
(0.361)\end{array}$ \\
\hline Family labor use & $\begin{array}{c}0.757 \\
(0.515)\end{array}$ & $\begin{array}{l}0.961 * \\
(0.536)\end{array}$ & $\begin{array}{c}0.808 \\
(0.532)\end{array}$ \\
\hline Hired labor use & $\begin{array}{c}-0.427 \\
(0.279)\end{array}$ & $\begin{array}{c}-0.337 \\
(0.226)\end{array}$ & $\begin{array}{c}-0.419 \\
(0.275)\end{array}$ \\
\hline Internet access & $\begin{array}{c}-0.277 \\
(0.256)\end{array}$ & $\begin{array}{c}-0.401 * \\
(0.221)\end{array}$ & $\begin{array}{c}-0.376^{*} \\
(0.218)\end{array}$ \\
\hline Years of farming & $\begin{array}{c}-0.003 \\
(0.004)\end{array}$ & $\begin{array}{l}0.008 * \\
(0.005)\end{array}$ & $\begin{array}{c}0.005 \\
(0.005)\end{array}$ \\
\hline Location (Base: Delaware stat & & & \\
\hline Maryland & $\begin{array}{l}-0.501 * * * \\
(0.182)\end{array}$ & $\begin{array}{l}0.509 * * * \\
(0.114)\end{array}$ & $\begin{array}{l}-0.437 * * * \\
(0.129)\end{array}$ \\
\hline Tennessee & $\begin{array}{c}-0.689 \\
(0.168)\end{array}$ & $\begin{array}{c}-0.968 \\
(0.201) \\
\end{array}$ & $\begin{array}{l}-0.818 * * * \\
(0.185)\end{array}$ \\
\hline $\begin{array}{l}\text { Log pseudolikelihood } \\
\text { AIC }\end{array}$ & $\begin{array}{r}-291783.74 \\
7578.98\end{array}$ & $\begin{array}{r}-278424.75 \\
7231.99\end{array}$ & $\begin{array}{r}-309149.50 \\
8030.04\end{array}$ \\
\hline
\end{tabular}

Standard errors are in parentheses; standard errors are robust standard errors adjusted for 8 clusters; Parameters are estimated using generalized linear models with family (poisson) \& link (log); * **, *** indicate 10\%, 5\%, and 1\% level of significance, respectively. 
Since centrality measures are correlated, we used five separate equations to estimate the effects of degree-in, degree-out, closeness-in, closeness-out, and betweenness, controlling for several other variables. Table 3 shows the results from three equations $^{2}$ representing separately estimated effects of degree-in, degree-out, and betweenness centralities. We found a positive and highly significant impact of each centrality measure on farm sales. Overall, our results confirm a significantly positive relationship of sales with involvement in the network. However, consistent with our expectations, the magnitude of impact is different as these centralities indicate the different ways of involvement and ability in the network-indicators of number of connections (degree centrality), proximity or distance of the actors in terms of information access (closeness centralities), and control of information flow (betweenness centrality).

A positive 0.188 coefficient of degree-in centrality suggests that expected farm sales increase with the number of farmers who know or connect to the farmer in question. A unit increase, essentially an additional farmer connection (link) to the node, is associated with an increase in farm sales of around $19 \%$. The higher number of connections likely helps farmers to acquire knowledge and access new technologies and other innovations in farm-related news. This knowledge and information exchange and discussion with these connections may, in turn, help enhance farm sales. Similarly, a positive coefficient of degree-out centrality suggests that sales increase as a farmer connects to more other farmers. A coefficient of 0.246 indicates that a one-unit increase, essentially an additional farmer connection (out) from the node, increases farm sales by $24.6 \%$. This also means that being more sociable within the overall network conveys a small advantage over merely being more popular, in terms of expanded sales. Therefore, how many other farmers connect to a farmer and how many other farmers a farmer connects to both play an important role, but the latter has an even higher magnitude of impact on sales.
Additionally, a significantly positive effect of betweenness centrality on farm sales suggests that sales volume increases as the farmer's power to control information flow increases. Interestingly, we found around $3.4 \%$ higher farm sales for each one-point increase in betweenness centrality. Essentially, betweenness centrality is the measure counting the number of times the farmer is between the path (flow) of other farmers. Thus, the positive effect suggests that the key farmers having a higher degree of ability to control the flow of information also generates higher sales.

Several other variables influence farm sales, which are included in the models (Table 4). The coefficient on age across all equations suggests that farmers aged 36 to 54 years have higher sales, as compared to farmers below age 35 . We also found a significantly positive effect of education, as indicated by coefficients of high school, college, and graduate education variables, consistent across all equations. The positive effect of age and education is plausible as older and more educated farmers gather farm experience or knowledge over time, which helps in various ways to increase farm sales. We also found effects of gender and race on farm sales. Specifically, female-owned or -operated farms generate lower sales than those operated by males. Also, our results across all equations suggest that operators or farmers belonging to African American, Hispanic, Asian, or multiracial ethnicities/races generate lower farm sales, as compared to White counterparts.

The results also show that full time farmers have fewer farm sales when degree-in and degreeout are used as centrality measures: in these equations, full time farmers have lower sales than part time farmers. In contrast, the effect is positive when we use betweenness as a centrality measure. The reason for this is not completely transparent and requires further research. It is possible that full-time farmers grow more non-specialty crops, which were not considered in this particular study, but this does not explain why the sign on the coefficient flips in model 3 (this is the only variable for

2 Although we also estimated equations representing the effect of closeness-in and closeness-out centralities, we have not presented these here due to space limitations. Moreover, we found the effect of closeness centralities to be significantly positive, consistent with other centrality measures. 
which this happens). Somehow, for full-time farmers the fact of being "between" the connections of more other farmers enhances farm sales, compared to simply having more in- or out-connections alone. The effect of internet access also has results counter to expectation (and in contrast to the findings from Khanal, Mishra, and Koirala, 2015)_our results show significantly negative effects on farm sales, across all equations. If the internet is only used to engage in social media, rather than to seek information related to the farm business, such access could in fact reduce farm productivity and thus lower farm sales.

\section{Summary and Conclusion}

The extent of interaction, network structure, and type of agricultural informants are as crucial to information exchange, knowledge transfer, and technology diffusion in farming as they are in other industries. This is even more important for small farms, and especially those located in rural areas. SNA is a powerful tool that may guide social planning, outreach, and dissemination policy and help to answer important questions, such as how small farmers connect to each other, cluster with one another, and seek information, production, and marketing advice. This study conducted SNA of small farmers and analyzed factors influencing network participation and the impact of network positions on financial performance. We find several demographic and socio-economic factors influencing the network centrality of small farmers. Specifically, age, educational attainment, gender, farm hours and labor use, as well as location factors significantly influence network positions. Additionally, the farmer's network position significantly affected their specialty crop sales, regardless of the network centrality measure used-higher centrality (more central, more connection, higher ability to control information) positively influences farm sales.

Our findings may be helpful for community development researchers, economists, and Extension educators in understanding farmer networking processes and structures, and in developing information delivery strategies that are sensitive to the network-specific attributes of each farmer. With SNA it is possible to reach many farmers and identify key contacts and key informants, especially in minority and underserved communities, who otherwise may not have direct contact with mainstream Extension. Consistent with our expectation, networking is crucial for production-, marketing-, and resource-sharing aspects while magnitudes of impact differ by the centrality measure used. Different centrality positions indicate different aspects of involvement such as being popular, having more connections, having control of information, and having the ability to quickly receive or pass information. Farmers' centrality positions within the different networks are influenced by several demographic factors. In addition, centrality positions still have independent effects on sales of specialty crops even after we control for key demographic factors, including educational attainment.

More generally, for Extension educators and practitioners, our study shows that SNA can serve to identify key individuals within a farming community (network) who can most effectively disseminate information because they are popular and have prestige or the trust of other community members. Likewise, SNA can help identify gregarious individuals who can quickly disseminate information because they are connected to many other individuals in the community. Of course, such knowledge needs to be used with caution, as it could be abused (e.g., to distribute false information). Of equal interest, an SNA can be used to identify farmers within a network who may require additional effort in targeting, because they are on the fringe of the network. For example, in our communities, females had fewer out-degrees than males while multiracial individuals had fewer in-degrees than Whites. Multiracial individuals also had fewer sales of specialty crops, holding the centrality measure constant, and suggesting that they may benefit from additional attention by Extension educators. Those who were not married also had fewer in-degrees, indicating they may not receive as much information from the network as their married peers. A similar analysis could be conducted for the betweenness and closeness scores, but this was beyond the scope of the current study.

Finally, we discuss a few limitations of our work. First, our econometric estimation is constrained by limited data from survey responses; having a larger sample size could yield more robust 
inferences. Second, we caution readers that our findings should not be used to infer complete cause-and-effect relations and should instead be interpreted as directional associations and correlations under given assumptions. More rigorous investigations toward estimating causal inferences could be a topic for future research. The work pre- sented in this paper suggests that further investments in research on farmers' social networks could have high payoffs. Moreover, it would be of great interest to compare the networks measured here with those derived from other farmers elsewhere in the U.S., who are not minorities or smallfarm operators.

\section{References}

Beratan, K., Jackson, P., \& Godette, S. (2014). Fostering capacity building among groups of disadvantaged farmers, southeastern North Carolina (USA). Journal of Agriculture, Food Systems, and Community Development, 4(3), 61-78. https://doi.org/10.5304/jafscd.2014.043.001

Boahene, K., Snijders, T. A., \& Folmer, H. (1999). An integrated socioeconomic analysis of innovation adoption: The case of hybrid cocoa in Ghana. Journal of Policy Modeling, 21(2), 167-184. https://doi.org/10.1016/S0161-8938(97)00070-7

Christensen, L. O., \& O’Sullivan, R. (2015). Using social network analysis to measure changes in regional food systems collaboration: A methodological framework. Journal of Agriculture, Food Systems, and Community Development, 5(3), 113129. https://doi.org/10.5304/jafscd.2015.053.013

Coleman, J. S. (1990). Foundations of social theory. Cambridge, MA: Harvard University Press.

Conley, T. G., \& Udry, C. R. (2010). Learning about a new technology: Pineapple in Ghana. American Economic Review, 100(1), 35-69. https://doi.org/10.1257/aer.100.1.35

Dunning, R., Creamer, N., Lelekacs, J. M., O’Sullivan, J., Thraves, T., \& Wymore, T. (2012). Educator and institutional entrepreneur: Cooperative Extension and the building of localized food systems. Journal of Agriculture, Food Systems, and Community Development, 3(1), 99-112. https://doi.org/10.5304/jafscd.2012.031.010

Flora, C. B., \& Flora, J. L. (2008). Rural communities: Legacy and change. Philadelphia: Westview Press.

Freeman, L. C. (1978). Centrality in social networks conceptual clarification. Social Networks, 1(3), 215-239. https://doi.org/10.1016/0378-8733(78)90021-7

Han, Y., \& Goetz, S. J. (2019). Measuring network rewiring over time. PLOS ONE, 14(7), e0220295. https://doi.org/10.1371/journal.pone.0220295

Hauck, J., Schmidt, J., \& Werner, A. (2016). Using social network analysis to identify key stakeholders in agricultural biodiversity governance and related land-use decisions at regional and local level. Ecology and Society, 21 (2), 49. https://doi.org/10.5751/ES-08596-210249

Hoffman, M., Lubell, M., \& Hillis, V. (2015). Network-smart extension could catalyze social learning. California Agriculture, 69(2), 113-122. https://doi.org/10.3733/ca.E.v069n02p113

Keskitalo, E. C. H., Baird, J., Laszlo Ambjörnsson, E., \& Plummer, R. (2014). Social network analysis of multi-level linkages: A Swedish case study on northern forest-based sectors. Ambio, 43(6), 745-758. https://doi.org/10.1007/s13280-014-0492-0

Khanal, A. R., \& Mishra, A. K. (2014). Agritourism and off-farm work: Survival strategies for small farms. Agricultural Economics, 45 (S1), 65-76. https://doi.org/10.1111/agec.12130

Khanal, A. R., Mishra, A. K., \& Koirala, K. H. (2015). Access to the Internet and financial performance of small business households. Electronic Commerce Research, 15(2), 159-175. https://doi.org/10.1007/s10660-015-9178-3

Kim, S., \& Shin, E.-H. (2002). A longitudinal analysis of globalization and regionalization in international trade: A social network approach. Social Forces, 81(2), 445-468. Retrieved from https://www.jstor.org/stable/3086478

Lyon, F. (2000). Trust, networks and norms: The creation of social capital in agricultural economies in Ghana. World Development, 28, 663-681. https://doi.org/10.1016/S0305-750X(99)00146-1

McClure, K. R., Frierson, L., Hall, A. W., \& Ostlund, K. L. (2017). Philanthropic giving by foundations to higher education institutions: A state-level social network analysis. Philanthropy \& Education, 1(1), 1-28. https://doi.org/10.2979/phileduc.1.1.02 
Meenar, M. R., \& Hoover, B. M. (2012). Community food security via urban agriculture: Understanding people, place, economy, and accessibility from a food justice perspective. Journal of Agriculture, Food Systems, and Community Development, 3(1), 143-160. https://doi.org/10.5304/jafscd.2012.031.013

Opsahl, T., Agneessens, F., \& Skvoretz, J. (2010). Node centrality in weighted networks: Generalizing degree and shortest paths. Social Networks, 32(3), 245-251. https://doi.org/10.1016/j.socnet.2010.03.006

Pratiwi, A., \& Suzuki, A. (2017). Effects of farmers' social networks on knowledge acquisition: Lessons from agricultural training in rural Indonesia. Journal of Economic Structures, 6(1), 8. https://doi.org/10.1186/s40008-017-0069-8

Prell, C., Hubacek, K., \& Reed, M. (2009). Stakeholder analysis and social network analysis in natural resource management. Society and Natural Resources, 22(6), 501-518. https://doi.org/10.1080/08941920802199202

Richerson, P. J., \& Boyd, R. (2005). Not by genes alone: How culture transformed human evolution. Chicago: University of Chicago Press.

Rupasingha, A., \& Goetz, S. J. (2007). Social and political forces as determinants of poverty: A spatial analysis. Journal of Socio-Economics, 36(4), 650-671. https://doi.org/10.1016/j.socec.2006.12.021

Shaw, L., Lubell, M., \& Ohmart, C. (2011). The evolution of local partnerships for sustainable agriculture. Society and Natural Resources, 24(10), 1078-1095. https://doi.org/10.1080/08941920.2010.550384 